\title{
Primary health care use and health care accessibility among adolescents in the United Arab Emirates
}

\author{
C. Barakat-Haddad ${ }^{7}$ and A. Siddiqua ${ }^{2}$
}

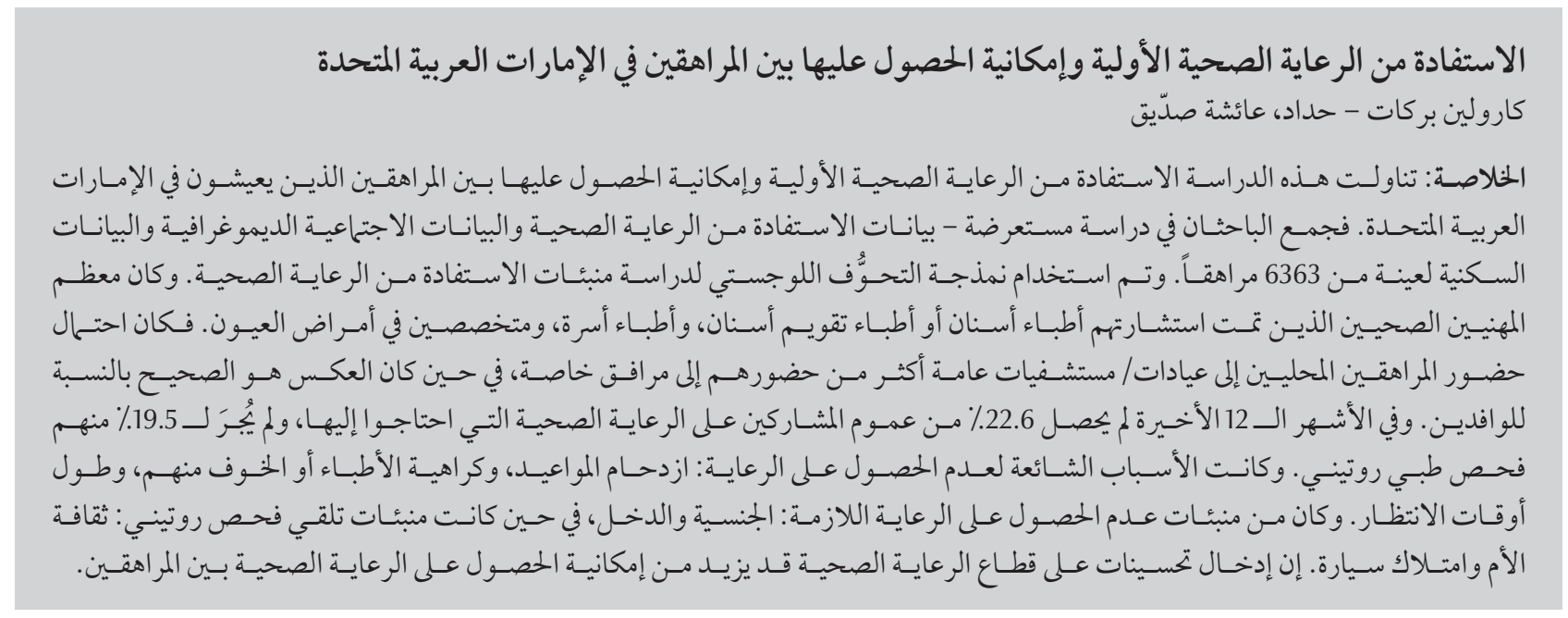

ABSTRACT This study examined primary health care use and accessibility among adolescents living in the United Arab Emirates. In a cross-sectional study, we collected health care use, sociodemographic and residential data for a sample of 6363 adolescents. Logistic regression modelling was used to examine predictors of health care use. The most-consulted health professionals were dentists or orthodontists, family doctors and eye specialists. Local adolescents were more likely to attend public clinics/hospitals than private facilities, while the opposite was true for expatriates. In the previous 12 months $22.6 \%$ of the participants had not obtained the health care they needed and $19.5 \%$ had not had a routine health check-up. Common reasons for not obtaining care were busy schedules, dislike/fear of doctors and long waiting times. Predictors of not obtaining needed care included nationality and income, while those for having a routine check-up were mother's education and car ownership. Improvements to the health care sector may increase health care accessibility among adolescents.

Recours aux soins de santé primaires et accessibilité des soins de santé chez des adolescents aux Émirats arabes unis

La présente étude a examiné le recours aux soins de santé primaires et leur accessibilité chez des adolescents vivant aux Émirats arabes unis. Dans une étude transversale, nous avons recueilli des données sur le recours aux soins de santé, les lieux de résidence et des informations sociodémographiques dans un échantillon de 6363 adolescents. Un modèle de régression logistique a été appliqué pour examiner les facteurs prédictifs du recours aux soins de santé. Les professionnels de santé les plus consultés étaient les dentistes ou les orthodontistes, les médecins de famille et les ophtalmologistes. Les adolescents locaux avaient davantage tendance à consulter les hôpitaux/établissements de soins publics que les entités privées, contrairement aux expatriés. Au cours de 12 derniers mois, 22,6\% des participants dans l'ensemble avaient renoncé aux soins de santé dont ils avaient besoin et 19,5\% avaient renoncé à un bilan de santé systématique. Les raisons les plus fréquentes de non-recours aux soins étaient un emploi du temps chargé, une aversion/peur des médecins et la longueur des temps d'attente. Parmi les facteurs prédictifs de nonrecours aux soins nécessaires, on peut citer la nationalité et le revenu, tandis que ceux favorisant le recours à un bilan de santé systématique étaient le niveau d'études de la mère et le fait de posséder une voiture. Des améliorations dans le secteur des soins de santé pourraient améliorer l'accès des soins de santé aux adolescents. 


\section{Introduction}

Utilization of primary health care (PHC) services is an important determinant of health. Individuals who receive health care from $\mathrm{PHC}$ physicians are generally healthier than those who do not (1). Despite the importance of PHC use, there are many barriers to health care access that are experienced by populations in Arab countries (2). These include various geographical, cultural, financial and organizational barriers that can impact communities in different ways (2).

The United Arab Emirates (UAE) has a comprehensive public health care system and a private health sector (3). In 1986, the UAE federal government adopted the WHO Health for All strategy to help all people by the year 2000 achieve a level of health that will allow them to lead a socially and economically productive life (4). The federal government announced that the PHC approach was vital for achieving this goal (4). By 2000, 105 governmentfunded PHC clinics were established across the country, with most people living in proximity to PHC clinics (4). These health centres provide curative, preventive, health promotion and some rehabilitation services. However, there are indications that enhancements to the infrastructure and service at each of the centres are needed (5). These include higher levels of human, physical and economic resources to reduce the current geographical disparities in the quality of care offered at each of the PHC clinics.

In 2001, the UAE government terminated the policy of free health care for all residents and introduced service charges for expatriates, while care continued to be free for all UAE nationals (3). To access health care, expatriates can use medical insurance provided by their employers and apply for a health card issued by the Ministry of Health, which gives access to the public system. However, many foreign workers, particularly manual and semiskilled workers, do not have health insurance (3). This new health care delivery framework could affect access to care for the expatriate population compared with the local population.

Facilitating access to PHC is of particular relevance for the UAE adolescent sub-population for 3 main reasons. First, the UAE adolescent subpopulation constitutes over $16 \%$ of the national population and therefore has the potential to contribute significantly to the country's labour-intensive economy (6). Secondly, risk factors of many chronic diseases, including tobacco use, sedentary habits and poor diet, begin in adolescence (7), and therefore monitoring health outcomes during adolescence is particularly important. Thirdly, the majority of morbidity and mortality affecting adolescents - such that due to sexually transmitted infections, intentional and unintentional injuryare preventable (7). Thus, developing evidence-based policies that encourage screening for health problems and for risky behaviours are crucial for promoting health and yielding long-term health benefits among adolescents. Implementing effective public health strategies require knowledge of factors that influence PHC use in this subpopulation. To date, we are unaware of any studies that have focused on health care utilization among adolescents residing in the UAE. To address this gap in the literature, this study aimed: to describe health care use among UAE adolescents; to determine the profile of UAE adolescents who have travelled to another country for medication or treatment; and to determine the predictors of health care use among the UAE adolescent population.

\section{Methods}

\section{Data source and design}

This study utilized data from the $\mathrm{Na}$ tional Study of Population Health in the UAE (2007-2009) that was undertaken in collaboration with the UAE Ministry of Education. The programme consisted of developing and administering a comprehensive, large-scale, crosssectional survey to 6363 adolescents (aged 13-20 years) attending public and private schools in the 7 Emirates of the UAE (9 educational zones).

A minimum sample size of 5000 participants was arbitrarily selected in order to facilitate the examination of various health outcomes in this subpopulation. The study included a randomly selected stratified sample of 147 public and private secondary schools. School enrolment data from the UAE Ministry of Education (2005-2006 for private schools and 2006-2007 for public schools) was used in the stratification strategy. Three classes (one from each of grades 10, 11 and 12) from each selected school were randomly selected using the fishbowl method. All students registered to these selected classes were invited to participate in the study. The appropriate boards within the Ministry of Education and the Ministry of Health approved the study prior to administration of the survey.

The survey consisted of 2 components. The first component collected data on self-reported medical diagnoses, symptoms in relation to respiratory health, health care access and use, as well as demographic and socioeconomic data. The second component of the survey collected data related to residential mobility and locations, and residential characteristics. [more detailed information has been reported elsewhere (6)].

\section{Outcome and explanatory variables}

In addressing health care use, 5 items were used to determine outcome measures. These included the following: "In the past 12 months, have you seen or talked on the phone about your health with any of the following [list of health-care providers]?; "Where do you often go when you need health 
care?"; "During the past 12 months, was there ever a time when you felt that you needed health care but did not receive it?"; "Thinking of the most recent time, why didn't you get care?"; and "In the past two years, have you had a routine physical check-up without having a specific problem?"

In investigate travel abroad for health care, the following items were used: "Have you ever travelled for medication/treatment to other countries?"; and "Have you ever had an in-patient surgical operation?”

To determine the predictors of health care use, explanatory variables included data related to demographic, socioeconomic, residential and medical status variables. Participants' demographic profiles included data on sex, age, type of school attended, whether the participant was born in the UAE, ethnicity and parental education level. Nationality was classified on the basis of similar cultures, traditions, ancestral linkages or geographical origins. For socioeconomic profile, data on parents' employment was considered in the following categories: government employee, private employee, self-employed and not employed. Monthly family income was also included in the analyses. Data related to participants' residential profiles included location of residence: Abu Dhabi, Ajman, Dubai, Fujairah, Ras al-Khaimah, Sharjah, and Umm al-Quwain. To get a mobility profile, respondents were asked about the number of cars the household owned. For medical profile, an "any medical diagnosis" variable was computed to include any of the following conditions reported by the participants: chronic bronchitis, emphysema, chest conditions, skin conditions, arthritis, any respiratory problems, high blood pressure, heart disease, thalassemia, sickle-cell anaemia, any type of anaemia, diabetes, kidney problems, ulcer, cancer, migraine and thyroid condition. Data related to persistent wheeze included any wheezing or whistling of the chest in the past 12 months. Data related to persistent cough include any dry cough at night in the past 12 months other than when participants had a cold.

\section{Data analysis}

Data were analysed using SPSS, version 20. Descriptive statistics were calculated for outcome and explanatory variables. A series of bivariate analyses were completed for the expatriate and local populations. Chi-squared test was used to compare participants who felt they needed care but did not receive it with those who received needed care; to compare participants who had a routine physical check-up with those who did not; and to compare participants who travelled for medication or treatment to other countries with those who did not. All independent variables that were significant in the bivariate analyses were entered into logistic regression models to predict health care access outcomes. Therefore, for each of the expatriate and local populations, 3 logistic regression models were developed for not receiving care when needed, having a routine physical check-up without having a specific problem, and travelling for medication or treatment to other countries. For each of the modelled outcomes, forward stepwise entry of independent variables was conducted using significance level of $P \leq 0.05$.

Norman and Streiner proposed that logistic regression analyses require at least 10 subjects per parameter (8). Following this guideline, among the expatriate adolescent sub-population, the sample size of the regression models for not receiving care, for having a routine physical check-up without having a specific problem, and for travelling for medication or treatment to other countries should be 140, 70 and 30 respectively. These sample size requirements were met (613, 532 and 121 respectively). Similarly sample size requirements were met for the local adolescent population (579, 543 and 179 respectively).

\section{Results}

\section{Participants' sociodemographic and health profile}

Overall, $49.9 \%$ of participants in this study were classified as of local UAE origin, even though $75.4 \%$ were born in the UAE to parents of other nationalities. The mean age of the study sample was 16 years and $44.7 \%$ of participants were male. Detailed information in relation to the number of schools sampled and response rates has been published elsewhere (6). Table 1 summarizes the sociodemographic and health profiles of the study participants. Although there were some differences in relation to sociodemographic variables between the expatriate and local adolescent population in the UAE, the health profiles of these sub-populations appeared to be quite similar.

\section{Types of health-care providers consulted}

Table 2 shows the types of health-care providers that respondents had seen or talked to on the phone about their health in the last 12 months. Overall, the health-care providers which respondents were most likely to have consulted were dentists or orthodontists (20.6\%), followed by family doctors (13.6\%) and eye specialists (12.0\%).

For both local and expatriate adolescent sub-populations, more female participants had consulted health-care providers than had male participants, although more male participants had consulted with a chiropractor or physiotherapist and social worker, counsellor or psychologist than had the females (Figure 1).

\section{Types of services utilized}

Analysis of the types of services utilized shows that, overall, most participants reported attending private clinics or hospitals for needed health care (49.6\%), followed by public clinics or hospitals (44.4\%) (Table 2). 


\begin{tabular}{|c|c|c|c|c|c|c|}
\hline \multirow[t]{2}{*}{ Variable } & \multicolumn{2}{|c|}{ Expatriate } & \multicolumn{2}{|c|}{ Local } & \multicolumn{2}{|c|}{ Overall sample } \\
\hline & No. & $\%$ & No. & $\%$ & No. & $\%$ \\
\hline \multicolumn{7}{|l|}{ Sex } \\
\hline Male & 1515 & 48.3 & 1216 & 40.3 & 2791 & 44.7 \\
\hline Female & 1620 & 51.7 & 1798 & 59.7 & 3458 & 55.3 \\
\hline \multicolumn{7}{|l|}{ Age (years) } \\
\hline$\leq 14$ & 223 & 7.3 & 100 & 3.4 & 327 & 5.4 \\
\hline 15 & 926 & 30.2 & 736 & 25.0 & 1687 & 27.7 \\
\hline 16 & 894 & 29.2 & 869 & 29.5 & 1779 & 29.3 \\
\hline 17 & 729 & 23.8 & 876 & 29.8 & 1624 & 26.7 \\
\hline 18 & 198 & 6.5 & 232 & 7.9 & 437 & 7.2 \\
\hline$\geq 19$ & 93 & 3.0 & 128 & 4.4 & 228 & 3.7 \\
\hline \multicolumn{7}{|l|}{ School } \\
\hline Public & 1043 & 33.0 & 2773 & 90.4 & 3888 & 61.1 \\
\hline Private & 2114 & 67.0 & 293 & 9.6 & 2475 & 38.9 \\
\hline \multicolumn{7}{|l|}{ UAE born } \\
\hline No & 1334 & 42.6 & 187 & 6.2 & 1527 & 24.6 \\
\hline Yes & 1798 & 57.4 & 2826 & 93.8 & 4689 & 75.4 \\
\hline \multicolumn{7}{|l|}{ Parent's marital status } \\
\hline Married & 2866 & 92.4 & 2496 & 83.9 & 5438 & 88.1 \\
\hline Widowed & 59 & 1.9 & 170 & 5.7 & 237 & 3.8 \\
\hline Separated/divorced & 87 & 2.8 & 153 & 5.1 & 245 & 4.0 \\
\hline Other & 90 & 2.9 & 155 & 5.2 & 250 & 4.1 \\
\hline \multicolumn{7}{|l|}{ Nationality ${ }^{a}$} \\
\hline Arab (UAE) & - & - & 3108 & 49.9 & 3108 & 49.9 \\
\hline Arab (other GCC) & 214 & 7.9 & - & - & 357 & 5.7 \\
\hline Arab/Middle Eastern & 850 & 31.3 & - & - & 976 & 15.7 \\
\hline Arab/African & 512 & 18.8 & - & - & 620 & 10.0 \\
\hline South - East Asian & 995 & 36.6 & - & - & 1001 & 16.1 \\
\hline Western & 80 & 2.9 & - & - & 82 & 1.3 \\
\hline None/other & 69 & 2.5 & - & - & 79 & 1.3 \\
\hline \multicolumn{7}{|c|}{ Father graduated from high school } \\
\hline No & 547 & 20.9 & 1568 & 65.1 & 2150 & 42.2 \\
\hline Yes & 2068 & 79.1 & 841 & 34.9 & 2948 & 57.8 \\
\hline \multicolumn{7}{|c|}{ Mother graduated from high school } \\
\hline No & 817 & 31.1 & 1763 & 72.6 & 2613 & 51.0 \\
\hline Yes & 1806 & 68.9 & 665 & 27.4 & 2515 & 49.0 \\
\hline \multicolumn{7}{|l|}{ Father's employment } \\
\hline Government employee & 991 & 37.1 & 1419 & 59.0 & 2451 & 46.8 \\
\hline Private employee & 1015 & 38.0 & 178 & 7.4 & 1216 & 23.2 \\
\hline Self-employed & 478 & 17.9 & 242 & 10.1 & 730 & 11.5 \\
\hline Not employed & 184 & 6.9 & 566 & 23.5 & 764 & 12.0 \\
\hline \multicolumn{7}{|l|}{ Mother's employment } \\
\hline Government employee & 255 & 9.4 & 259 & 10.1 & 522 & 9.7 \\
\hline Private employee & 334 & 12.3 & 55 & 2.2 & 394 & 7.3 \\
\hline Self-employed & 99 & 3.6 & 37 & 1.4 & 141 & 2.6 \\
\hline Not employed & 2038 & 74.8 & 2201 & 86.2 & 4312 & 80.3 \\
\hline
\end{tabular}




\begin{tabular}{|c|c|c|c|c|c|c|}
\hline \multirow[t]{2}{*}{ Variable } & \multicolumn{2}{|c|}{ Expatriate } & \multicolumn{2}{|c|}{ Local } & \multicolumn{2}{|c|}{ Overall sample } \\
\hline & No. & $\%$ & No. & $\%$ & No. & $\%$ \\
\hline \multicolumn{7}{|c|}{ Monthly household income (AED) } \\
\hline$<2000$ & 90 & 4.4 & 69 & 3.9 & 165 & 2.6 \\
\hline$>2-\leq 5000$ & 548 & 26.5 & 330 & 18.8 & 892 & 23.0 \\
\hline$>5-\leq 8000$ & 386 & 18.7 & 284 & 16.2 & 683 & 17.6 \\
\hline$>8-\leq 10000$ & 243 & 11.8 & 219 & 12.5 & 472 & 12.2 \\
\hline$>10-\leq 12000$ & 172 & 8.3 & 175 & 10.0 & 352 & 9.1 \\
\hline$>12-\leq 15000$ & 182 & 8.8 & 136 & 7.7 & 321 & 8.3 \\
\hline$>15-\leq 20000$ & 143 & 6.9 & 141 & 8.0 & 288 & 7.4 \\
\hline$>20000$ & 302 & 14.6 & 401 & 22.8 & 709 & 18.3 \\
\hline \multicolumn{7}{|c|}{$\begin{array}{l}\text { Household income (combined categories) } \\
(A E D)^{b}\end{array}$} \\
\hline$<15000$ & 1723 & 81.4 & 1113 & 65.2 & 2885 & 74.3 \\
\hline$\geq 15000$ & 395 & 18.6 & 593 & 34.8 & 997 & 25.7 \\
\hline \multicolumn{7}{|l|}{ Emirate of residence } \\
\hline Abu Dhabi & 1626 & 51.5 & 1309 & 42.7 & 3003 & 47.2 \\
\hline Ajman & 158 & 5.0 & 101 & 3.3 & 264 & 4.1 \\
\hline Dubai & 302 & 9.6 & 280 & 9.1 & 589 & 9.3 \\
\hline Fujairah & 165 & 5.2 & 347 & 11.3 & 521 & 8.2 \\
\hline Ras al-Khaimah & 243 & 7.7 & 406 & 13.2 & 671 & 10.5 \\
\hline Sharjah & 605 & 19.2 & 535 & 17.4 & 1168 & 18.4 \\
\hline Umm al-Quwain & 58 & 1.8 & 88 & 2.9 & 147 & 2.3 \\
\hline \multicolumn{7}{|c|}{ No. of previous residences } \\
\hline 0 & 2001 & 63.4 & 2298 & 75.0 & 4410 & 69.3 \\
\hline 1 & 692 & 21.9 & 559 & 18.2 & 1267 & 19.9 \\
\hline 2 & 233 & 7.4 & 116 & 3.8 & 355 & 5.6 \\
\hline 3 & 122 & 3.9 & 50 & 1.6 & 175 & 2.8 \\
\hline 4 & 109 & 3.5 & 43 & 1.4 & 156 & 2.5 \\
\hline \multicolumn{7}{|l|}{ No. of household cars } \\
\hline 0 & 197 & 6.4 & 60 & 2.0 & 258 & 4.2 \\
\hline $1-3$ & 2485 & 80.8 & 1414 & 47.9 & 3933 & 64.5 \\
\hline $4-6$ & 281 & 9.1 & 1001 & 33.9 & 1302 & 21.4 \\
\hline 7-9 & 65 & 2.1 & 309 & 10.5 & 382 & 6.3 \\
\hline$\geq 10$ & 47 & 1.5 & 165 & 5.6 & 219 & 3.6 \\
\hline \multicolumn{7}{|c|}{ Any medical diagnosis } \\
\hline No & 2332 & 75.2 & 2190 & 72.4 & 3066 & 49.3 \\
\hline Yes & 768 & 24.8 & 833 & 27.6 & 3157 & 50.7 \\
\hline \multicolumn{7}{|l|}{ Persistent wheeze } \\
\hline No & 2673 & 87.6 & 2581 & 88.3 & 5346 & 87.8 \\
\hline Yes & 379 & 12.4 & 341 & 11.7 & 741 & 12.2 \\
\hline \multicolumn{7}{|l|}{ Persistent cough } \\
\hline No & 2009 & 65.8 & 1905 & 64.6 & 3985 & 65.2 \\
\hline Yes & 1042 & 34.2 & 1046 & 35.4 & 2126 & 34.8 \\
\hline
\end{tabular}

${ }^{a}$ Arab (other GCC) = Kuwait, Saudi Arabia, Oman, Qatar, Bahrain, Yemen; Arab/Middle Eastern = Lebanon, Syrian Arab Republic, Jordan, Palestine, Iraq; Arab/African = Egypt, Tunisia, Morocco, Algeria, Libya, Sudan, Somalia; South East Asian = India, Pakistan, Bangladesh, Sri Lanka, Philippines, Indonesia; Western = Europe, United States of America, Australia, Canada; No nationality and other = all other nationalities.

${ }^{b}$ Cut-off based on data from the UAE Ministry of Economy indicating that the average monthly income for Emirati households was AED 36438.10 and that for expatriate households was AED 15074.30 (20)

AED = United Arab Emirates dirham; GCC = Gulf Cooperation Council; - = not applicable. 


\begin{tabular}{|c|c|c|}
\hline Variable & No. & $\%$ \\
\hline \multicolumn{3}{|l|}{ Health-care providers attended (past 12 months) } \\
\hline Family doctor & 848 & 13.6 \\
\hline Eye specialist & 743 & 12.0 \\
\hline Nurse/pharmacist & 317 & 5.1 \\
\hline Dentist/orthodontist & 1280 & 20.6 \\
\hline Chiropractor/physiotherapist & 76 & 1.2 \\
\hline Social worker/counsellor/psychologist & 95 & 1.5 \\
\hline Nutritionist & 247 & 4.0 \\
\hline \multicolumn{3}{|l|}{ Type of health-care resource utilized } \\
\hline Private clinic/hospital & 2911 & 49.6 \\
\hline Public clinic/hospital & 2606 & 44.4 \\
\hline School clinic & 207 & 3.5 \\
\hline Telephone consultation & 44 & 0.7 \\
\hline Internet & 106 & 1.8 \\
\hline Did not obtain needed health care & 1224 & 22.6 \\
\hline \multicolumn{3}{|l|}{ Reason for not obtaining needed care } \\
\hline None available in the area & 172 & 10.0 \\
\hline Not available at the time required & 151 & 8.8 \\
\hline Waiting time too long & 265 & 15.5 \\
\hline Cost & 211 & 12.3 \\
\hline Too busy & 596 & 34.7 \\
\hline Didn't know where to go & 197 & 11.6 \\
\hline Transport problems & 197 & 11.6 \\
\hline Language problems & 33 & 1.9 \\
\hline Dislike/fear of doctors & 340 & 19.8 \\
\hline Had a routine physical check-up & 1101 & 19.5 \\
\hline Travelled abroad for medication/treatment & 307 & 5.0 \\
\hline \multicolumn{3}{|l|}{ Top 5 locations for medication/treatment abroad } \\
\hline India & 60 & 1.4 \\
\hline Thailand & 37 & 0.8 \\
\hline Egypt & 33 & 0.7 \\
\hline Germany & 26 & 0.5 \\
\hline United States of America & 19 & 0.4 \\
\hline \multicolumn{3}{|l|}{ Medical condition/reason for travel abroad } \\
\hline Eye problem & 22 & 0.4 \\
\hline Tonsillectomy & 11 & 0.2 \\
\hline Allergy problem & 10 & 0.2 \\
\hline Other operation & 5 & 0.1 \\
\hline Had inpatient surgical operation & 992 & 16.5 \\
\hline \multicolumn{3}{|l|}{ Top 5 locations for inpatient operation } \\
\hline United Arab Emirates & 755 & 18.7 \\
\hline Egypt & 34 & 0.7 \\
\hline India & 25 & 0.5 \\
\hline Syrian Arab Republic & 22 & 0.4 \\
\hline Jordan & 19 & 0.3 \\
\hline \multicolumn{3}{|l|}{ Top 5 conditions/reasons for inpatient operation } \\
\hline Appendicitis & 107 & 2.5 \\
\hline Tonsillitis & 142 & 3.4 \\
\hline Broken bone & 53 & 1.2 \\
\hline Ear problem & 21 & 0.1 \\
\hline Stitches & 21 & 0.4 \\
\hline
\end{tabular}

For both the local and expatriate adolescent sub-populations, more females had been to private clinics or hospitals than males, while males were more likely to have used public clinics or hospitals (Figure 2). In general, more local adolescents had attended public clinics or hospitals, while more expatriate adolescents had attended private clinics of hospitals.

\section{Failure to get health care}

Overall, $22.6 \%$ of participants reported that, at any time in the last 12 months, they did not get the health care they needed (Table 2), with more females not obtaining needed health care than males (Figure 3). The 3 most common reasons for not obtaining health care were their own busy schedule (34.7\%), dislike/fear of doctors (19.8\%) and long waiting times at the doctor (15.5\%) (Table 2).

In the whole sample, more females reported not obtaining care due to dislike/fear of doctors than did males (Figure 4).

For the expatriate adolescent subpopulation, significant predictors of not getting health care when needed included: being born in the UAE; parents' marital status (widowed, separated/divorced, other); nationality (Arab/Middle Eastern, Arab/ African, none/other); income (AED $\geq 15$ 000-20 000); living in Ajman Emirate; having any medical diagnosis; having persistent wheeze; and having persistent cough (Table 3). For the local adolescent sub-population, significant predictors of not obtaining health care when needed included: income (AED < 2000); having any medical diagnosis; having persistent wheeze; and having persistent cough (Table 4).

\section{Routine physical health check- ups}

Overall, only $19.5 \%$ of participants had had a routine physical health checkup without having a specific problem (Table 2). 
(a) Overall population $(n=6363)$

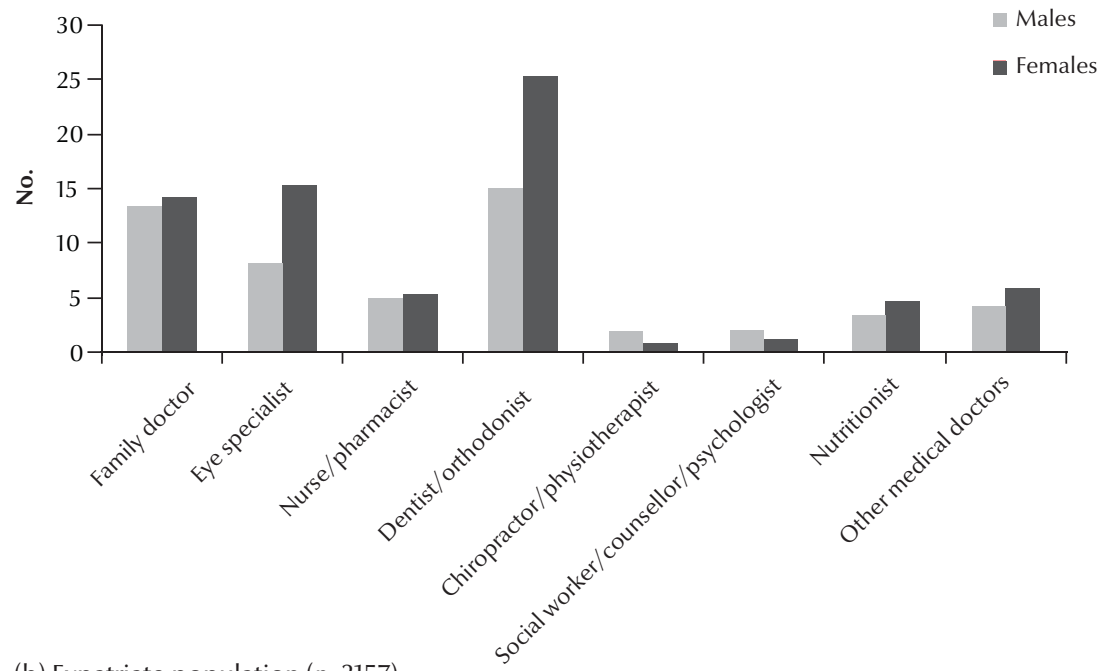

(b) Expatriate population $(n=3157)$

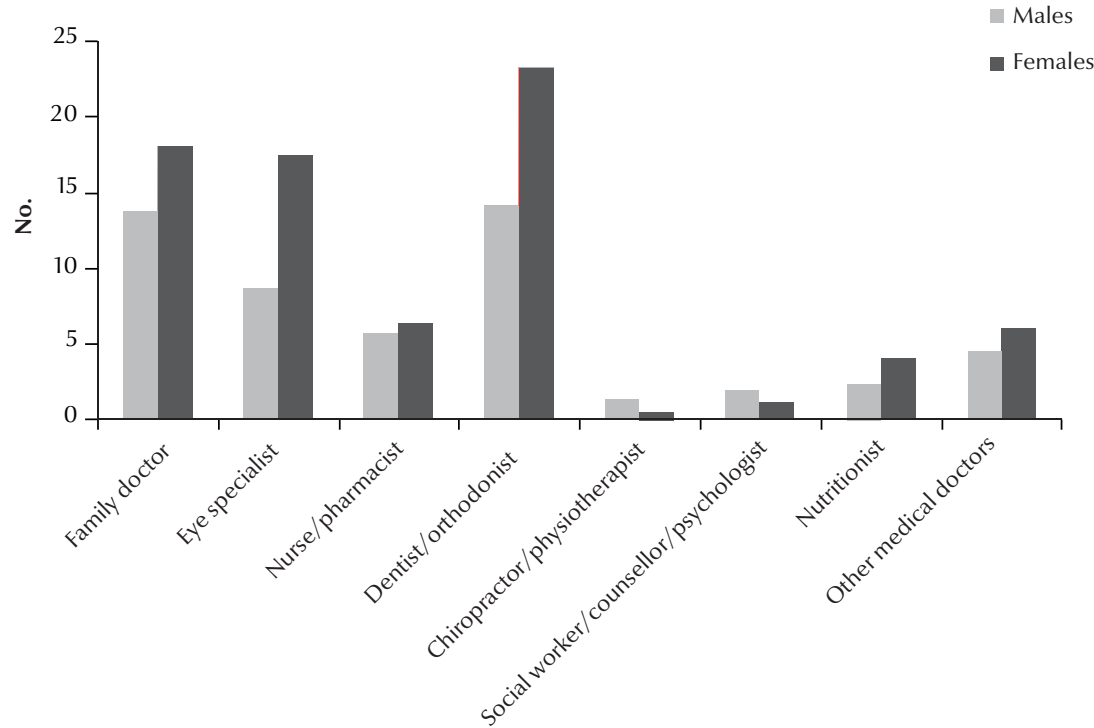

(c) Local population $(n=3066)$

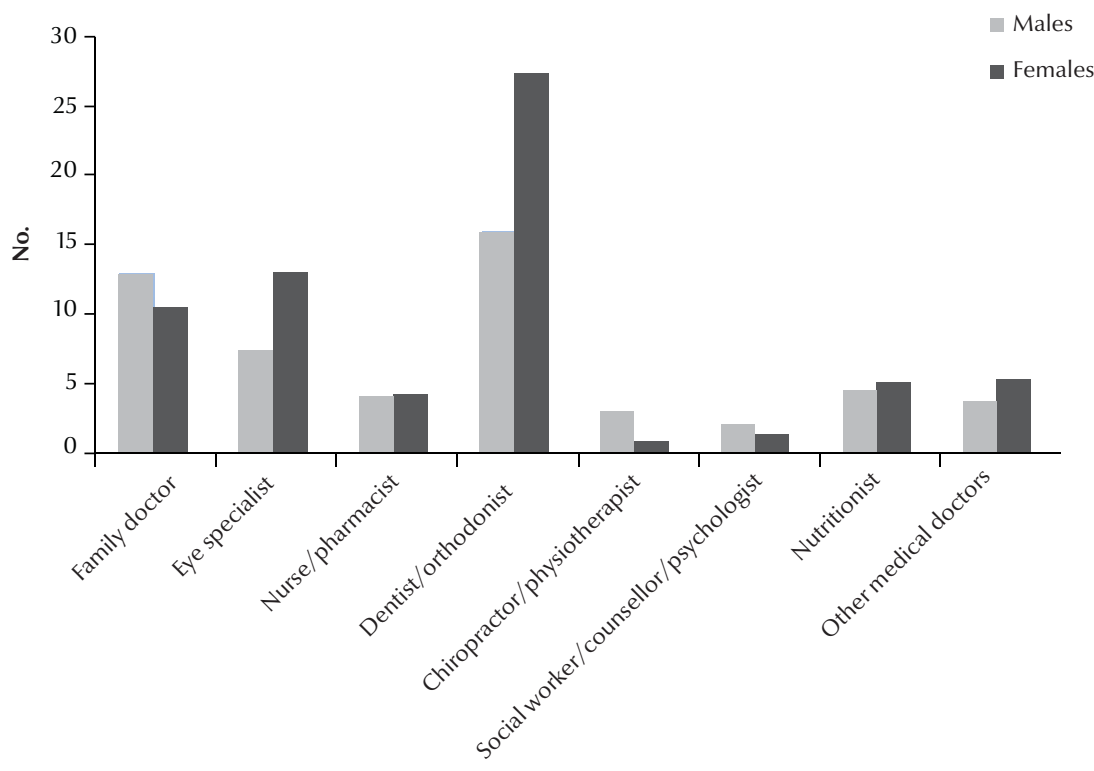

Figure 1 Types of health-care providers consulted in the past 12 months by adolescents residing in the United Arab Emirates
Across the overall and local populations, more females had a routine physical health check-up than males, while the opposite was true for the expatriate population (Figure 5).

For the expatriate adolescent sub-population, predictors of having a routine physical check-up without having a specific issue were: mother's education (completion of high school); living in Dubai Emirate; and the household owning 4-6 cars (Table 3). For the local adolescent sub-population, predictors of having a routine physical check-up were: household number of cars owned $(\geq 4)$ and having any medical diagnosis (Table 4).

\section{Travel to other countries for health care}

Overall, 5.0\% of participants had travelled to another country for medication/ treatment (Table 2). More local participants had travelled abroad for medication/ treatment than expatriate participants, with this trend being more pronounced among females (Figure 6).

For the expatriate adolescent subpopulation, predictors of travelling to another country for medication/treatment included: having any medical diagnosis; and having persistent wheeze (Table 3). For the local adolescent subpopulation, predictors of travelling to another country for medication/treatment included: mother's employment (government sector); having any medical diagnosis; and having persistent wheeze (Table 4).

\section{Received inpatient surgical operation}

Overall, $16.5 \%$ of participants had had an inpatient surgical operation (Table 2 ), with a higher prevalence among males (19.1\%) than females (14.2\%).

\section{Discussion}

Our study of health care use among adolescents from the UAE suggest that 
(a) Overall population $(n=5765)$

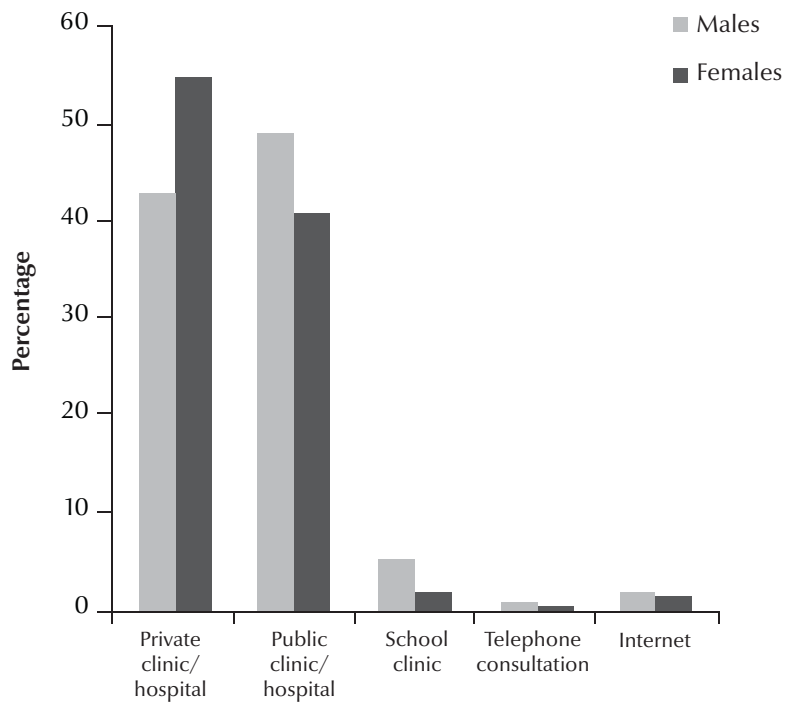

(b) Expatriate population $(n=2901)$

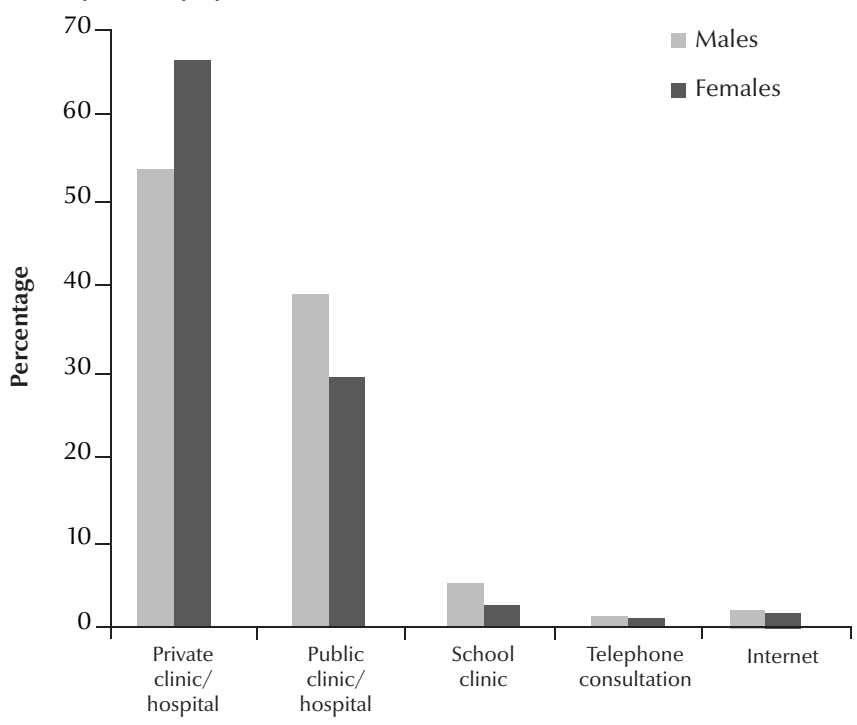

(a) Local population $(n=2864)$

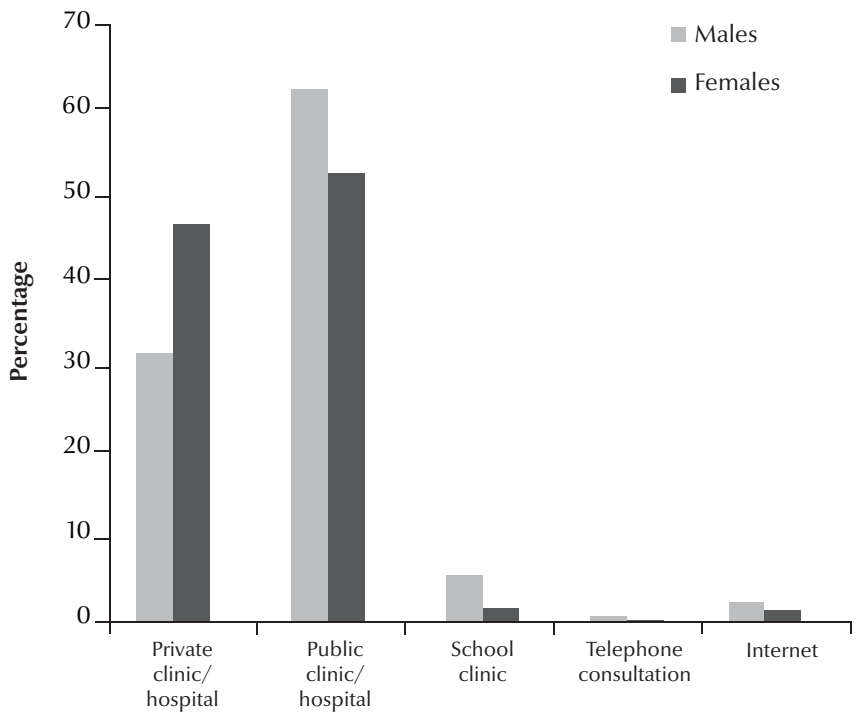

Figure 2 Types of health services utilized in the past 12 months by adolescents residing in the United Arab Emirates they most often consulted with a family doctor, an eye specialist and/or a dentist or orthodontist. Consistent with the literature, we found that females consulted health-care providers more than males did $(9,10)$. However, there is growing recognition that the differences in health-care seeking between the sexes is more complex than previously thought (10). Most studies that report a female excess in consulting are based on general practice and general population data and do not look at the types of symptoms and conditions reported by men and women (11). Also, categorizing by sex does not explain why some men seek care more often and why some women are reluctant to seek care (10). In order to develop strategies to improve utilization of care, we recommend that future research collects detailed information on symptoms and conditions related to seeking health care, and that it explores interactions between these factors and sex in order to better understand the observed sex difference in health care use among adolescents in the UAE. Specifically, we also recommend that future studies focus on examining health-care seeking on physical (including sexual) development and on sexual and reproductive health.

Our results indicate that most adolescents attended private or public clinics or hospitals for needed health care. This finding is not surprising, as alongside the public infrastructure, the private sector has become an important partner in providing health careservices to the population of the UAE in recent years (3). Interestingly, we found that females attended private clinics or hospitals more than males. Consistent with the health care delivery framework in the UAE that offers free health care to nationals, we found that expatriate adolescents visited private clinics or hospitals more than public clinics or hospitals for needed health care, whereas local adolescents sought care from 


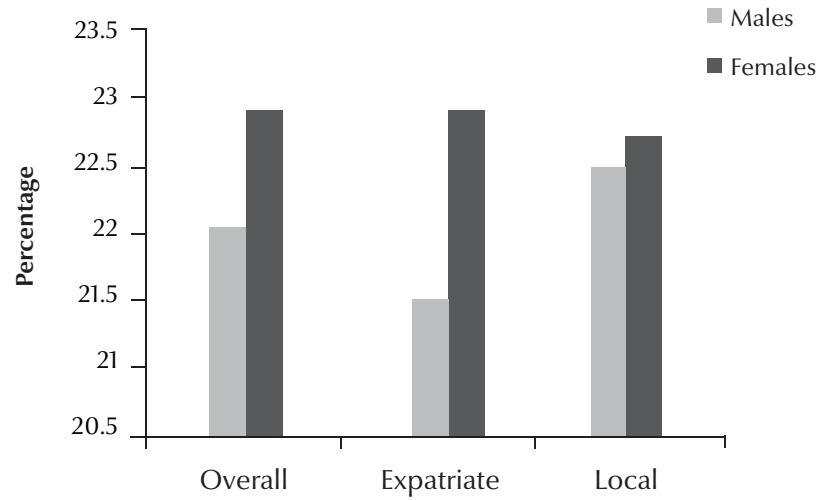

Figure 3 Failure to obtain needed health care by male and female local and expatriate adolescents residing in the United Arab Emirates $(n=5319$ overall; $n=2747$ expatriate; $n=2572$ local)

public clinics or hospitals more than from private clinics or hospitals.

It is concerning to note that many adolescents did not obtain health care when needed, and that females were more likely not to obtain the needed care than were males. Thus, although there is good coverage of health care facilities throughout the UAE, care is not always used by many adolescents, particularly females (3). Given the reported deficits at some $\mathrm{PHC}$ clinics, an increase in human, physical and economic resources has the potential to reduce waiting times and improve the accessibility of health services. A PlanDo-Study-Act (PDSA) improvement process, a strategy proven to successfully reduce waiting times in the United States, can also be implemented (12). The PDSA strategy works by identifying factors that contribute to long waiting room and examination room waiting times, determining opportunities for improvement, implementing one or more process improvement strategies and evaluating the impact of these strategies on improving wait times and patients' satisfaction with the care experience (12). Another effective strategy for reducing waiting times is advanced access scheduling, which seeks to provide improved access to timely (often same-day) appointments, does not limit the type of visits that can be provided in the same day and accommodates patients with urgent problems (13). Importantly, health education campaigns are needed to educate adolescents about the importance of seeking health care and to develop their time management skills and thus enabling access to health care services. These campaigns can also focus on informing adolescents where to go when care is needed. Improving public transport services or providing transportation allowances, strategies that have been proposed to reduce transportation barriers in underserved Western communities, can also be considered in the UAE to increase access to health facilities (14). Furthermore, with a particular focus on women, education programmes can be developed to teach people how to overcome their fear of doctors and the risks of delaying needed health care. Exposure-based strategies, which involve gradually confronting a feared situation until o+ne is no longer afraid, can be considered as they have been proven effective for overcoming fear of blood, needles, dentists and similar situations (15). Lastly, the relative high health care costs in the UAE can be a concern for the expatriate population (3).

Among expatriate adolescents residing in the UAE, our study found that predictors of not obtaining needed health care were being born in the $\mathrm{UAE}$ and parental marital status. In relation to place of birth, this predictor is likely linked to the lack of health insurance coverage among expatriates, even those that have potentially been residing in the UAE for a long period of time. In relation to parental marital status, it is interesting to note that research evidence from the United States suggests that access to health care among single-mother households varies by socioeconomic status, whereas access to health care for single-father households does not $(16,17)$. To determine whether similar patterns are present in the UAE population, future research should focus on stratifying our analyses by socioeconomic status. Our study also found that nationality, income, medical diagnoses and place of residence (Emirate) among expatriates were related to obtaining needed care. This uneven access to health care highlights the importance of implementing the compulsory health insurance scheme. Among the local population, our findings showed that adolescents with income AED < 2000 were less likely to obtain needed health care. Since health care is free for all nationals, we propose there are likely other barriers tied to socioeconomic status that affect accessibility to health care. We also found that adolescents with any medical diagnosis, persistent wheeze and persistent cough were less likely to obtain needed care, findings that are worthy of future investigation.

Our results showed that around $80 \%$ of adolescents did not have a routine physical health check-up. Naturally, implementing the strategies suggested above may increase the uptake of routine check-ups among adolescents. Our study found that, among expatriate adolescents, mother's level of education was related to routine physical health check-ups, a finding which is consistent with literature (18). We also found that 


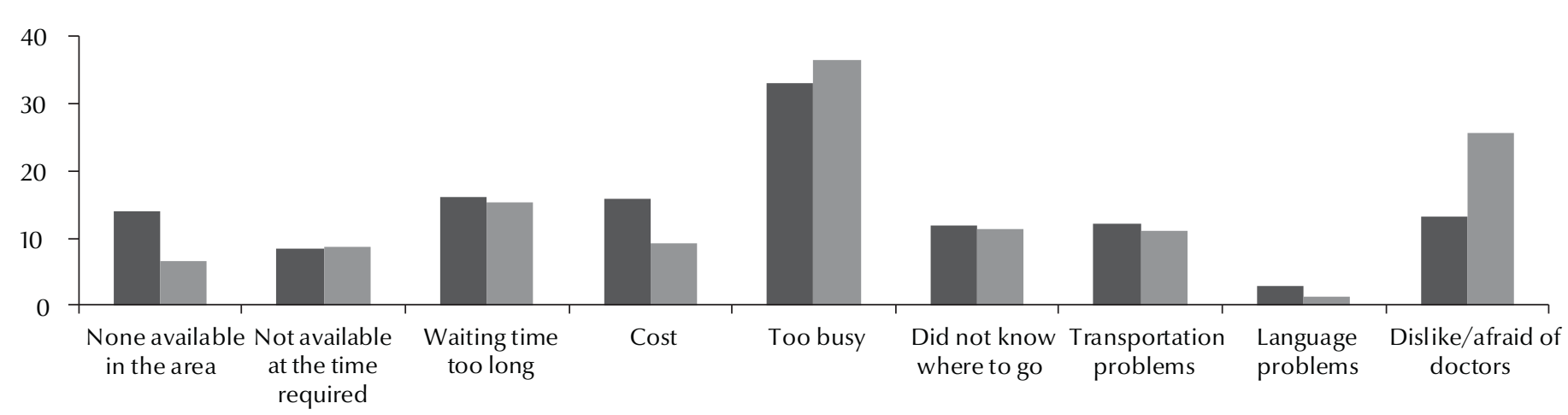

(b) Expatriate population $(n=3157)$

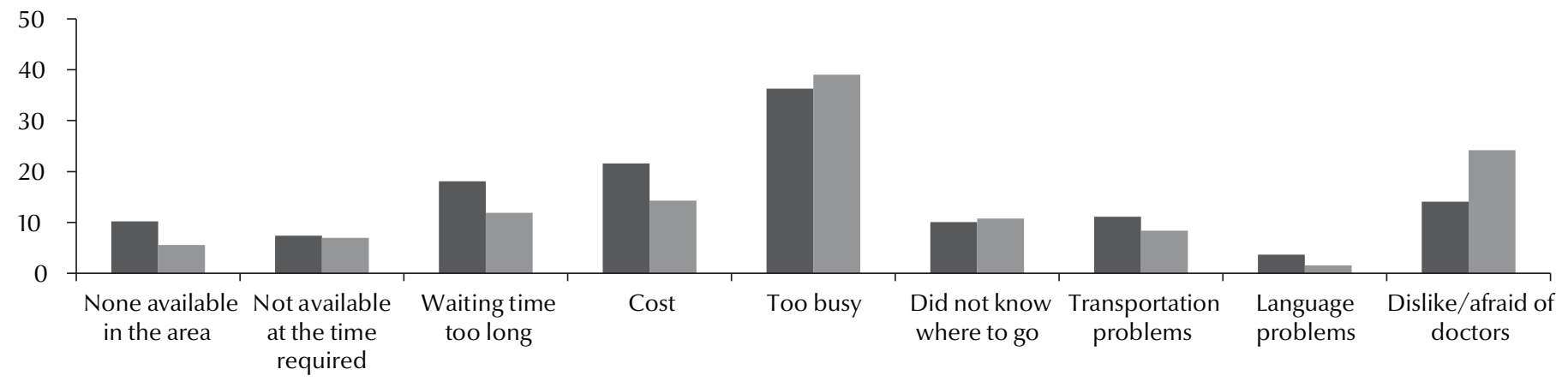

(c) Local population $(n=3066)$

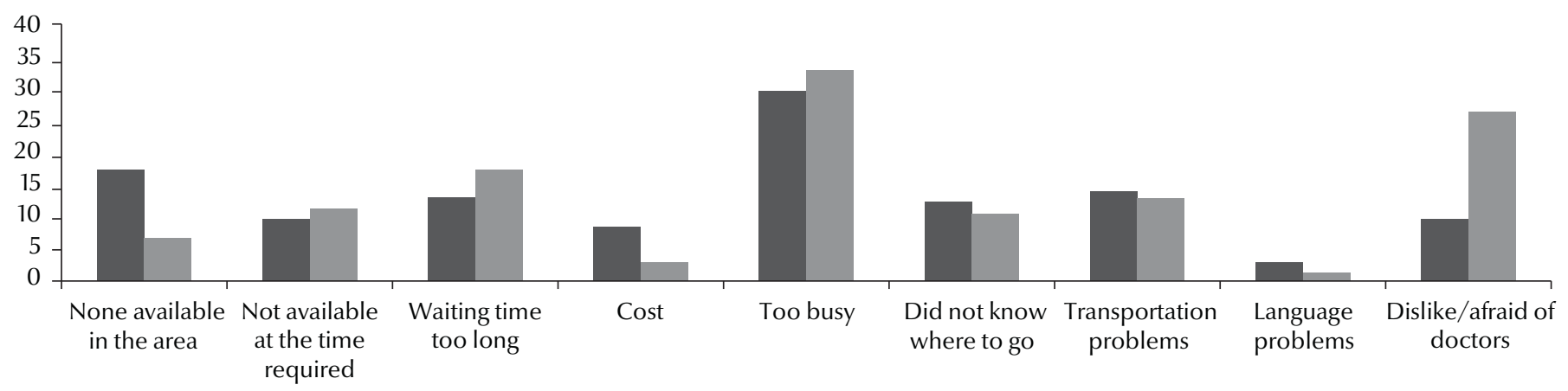

Figure 4 Reasons why of adolescents residing in the United Arab Emirates did not obtain health care: data for (a) overall population, (b) expatriate population and (c) local population

expatriate adolescents living in Dubai Emirate were more likely to have a routine check-up compared with those living in Abu Dhabi. This is interesting since the compulsory health insurance policy in Abu Dhabi should make health care more accessible for expatriates compared with Dubai (4). This result highlights that there is no single way of improving use of needed care and a variety of strategies may need to be implemented. Lastly, having a higher number of household cars and having a medical diagnosis were related to use of routine physical check-ups, demonstrating the importance of access to transport for health care $(14,16,17)$.

The finding that local adolescents were more likely to travel to other countries for medication or treatment than were expatriates is not surprising given that Health Authority Abu Dhabi offers payment to Emiratis to receive care abroad (19). We found that maternal employment and medical diagnoses appeared to be related to medical tourism. We suggest that future research examines in-depth the reasons and consequences of having to seek health care abroad.

This study was subject to several limitations. Datawere self-reported and 


\begin{tabular}{|c|c|c|c|c|}
\hline \multirow[t]{2}{*}{ Variable } & \multicolumn{2}{|c|}{ Expatriate } & \multicolumn{2}{|c|}{ Local } \\
\hline & OR & $95 \% \mathrm{Cl}$ & OR & $95 \% \mathrm{Cl}$ \\
\hline \multicolumn{5}{|l|}{ UAE born } \\
\hline No (ref.) & 1.00 & - & - & - \\
\hline Yes & 1.47 & $1.10-1.98^{*}$ & - & - \\
\hline \multicolumn{5}{|l|}{ Parents' marital status } \\
\hline Married (ref.) & 1.00 & - & 1.00 & - \\
\hline Widowed & 3.55 & $1.23-10.3^{*}$ & 1.70 & $0.99-2.90$ \\
\hline Separated/divorced & 2.48 & $1.08-5.69^{*}$ & 1.04 & $0.56-1.95$ \\
\hline Other & 2.79 & $1.21-6.46^{*}$ & 1.28 & $0.63-2.61$ \\
\hline \multicolumn{5}{|l|}{ Nationality } \\
\hline Arab (GCC country) & 1.84 & $0.99-3.41$ & - & - \\
\hline Arab/Middle Eastern & 1.53 & $1.03-2.28^{*}$ & - & - \\
\hline Arab/African & 1.98 & $1.28-3.05^{* *}$ & - & - \\
\hline South East Asian (ref.) & 1.00 & - & - & - \\
\hline Western & 1.80 & $0.67-4.88$ & - & - \\
\hline None/other & 3.67 & $1.59-8.43^{* *}$ & - & - \\
\hline \multicolumn{5}{|l|}{ Monthly household income (AED) } \\
\hline$<2000$ & 1.72 & $0.79-3.72$ & 3.01 & $1.44-6.28^{* *}$ \\
\hline$>2-\leq 5000$ & 1.06 & $0.64-1.76$ & 1.58 & $1.01-2.45$ \\
\hline$>5-\leq 8000$ & 0.93 & $0.55-1.58$ & 1.13 & $0.69-1.85$ \\
\hline$>8-\leq 10000$ & 0.74 & $0.41-1.33$ & 1.18 & $0.69-2.01$ \\
\hline$>10-\leq 12000$ & 0.92 & $0.49-1.70$ & 1.48 & $0.87-2.53$ \\
\hline$>12-\leq 15000$ & 0.74 & $0.39-1.38$ & 1.47 & $0.83-2.60$ \\
\hline$>15-\leq 20000$ & 1.91 & $1.03-3.54^{*}$ & 1.54 & $0.87-2.74$ \\
\hline > 20000 (ref.) & 1.00 & - & 1.00 & - \\
\hline \multicolumn{5}{|l|}{ Emirate of residence } \\
\hline Abu Dhabi (ref.) & 1.00 & - & - & - \\
\hline Ajman & 1.89 & $1.02-3.51^{*}$ & - & - \\
\hline Dubai & 1.10 & $0.65-1.86$ & - & - \\
\hline Fujairah & 1.55 & $0.74-3.23$ & - & - \\
\hline Ras al-Khaimah & 1.44 & $0.80-2.58$ & - & - \\
\hline Sharjah & 1.01 & $0.68-1.50$ & - & - \\
\hline Umm al-Quwain & 0.37 & $0.09-1.52$ & - & - \\
\hline \multicolumn{5}{|l|}{ Any medical diagnosis } \\
\hline No (ref.) & 1.00 & - & 1.00 & - \\
\hline Yes & 1.82 & $1.35-2.45^{* * *}$ & 2.49 & $1.85-3.35^{* * *}$ \\
\hline \multicolumn{5}{|l|}{ Persistent wheeze } \\
\hline No (ref.) & 1.00 & - & 1.00 & - \\
\hline Yes & 2.63 & $1.82-3.78^{* * *}$ & 1.93 & $1.29-2.90^{* *}$ \\
\hline \multicolumn{5}{|l|}{ Persistent cough } \\
\hline No (ref.) & 1.00 & - & 1.00 & - \\
\hline Yes & 1.76 & $1.32-2.34^{* * *}$ & 1.68 & $1.26-2.25^{* * *}$ \\
\hline \multicolumn{5}{|l|}{ Statistics } \\
\hline Hosmer \& Lemeshow $\chi^{2}$-value & & & & \\
\hline
\end{tabular}

${ }^{*} P<0.05$; ${ }^{* *} P<0.01$; ***P<0.001.

$($ ref. $)=$ reference category; $O R=$ odds ratio; $C l=$ confidence interval. 


\begin{tabular}{|c|c|c|c|c|}
\hline \multirow[t]{2}{*}{ Variable } & \multicolumn{2}{|c|}{ Expatriate } & \multicolumn{2}{|c|}{ Local } \\
\hline & OR & $95 \% \mathrm{Cl}$ & OR & $95 \% \mathrm{Cl}$ \\
\hline \multicolumn{5}{|l|}{ Mother completed high school } \\
\hline No (ref.) & 1.00 & - & - & - \\
\hline Yes & 1.52 & $1.08-2.13^{*}$ & - & - \\
\hline \multicolumn{5}{|l|}{ Emirate of residence } \\
\hline Abu Dhabi (ref.) & 1.00 & - & - & - \\
\hline Ajman & 0.55 & $0.27-1.15$ & - & - \\
\hline Dubai & 1.81 & $1.18-2.78^{* *}$ & - & - \\
\hline Fujairah & 0.83 & $0.39-1.74$ & - & - \\
\hline Ras al-Khaimah & 0.65 & $0.34-1.27$ & - & - \\
\hline Sharjah & 0.97 & $0.68-1.37$ & - & - \\
\hline Umm al-Quwain & 1.81 & $0.69-4.79$ & - & - \\
\hline \multicolumn{5}{|l|}{ No. of household cars } \\
\hline 0 (ref.) & 1.00 & - & 1.00 & - \\
\hline $1-3$ & 1.43 & $0.79-2.59$ & 2.95 & $0.91-9.61$ \\
\hline $4-6$ & 2.62 & $1.20-5.70^{*}$ & 4.52 & $1.39-14.7^{*}$ \\
\hline $7-9$ & 2.30 & $0.60-8.84$ & 4.57 & $1.37-15.2^{*}$ \\
\hline$\geq 10$ & 2.21 & $0.49-9.87$ & 4.14 & $1.20-14.3^{*}$ \\
\hline \multicolumn{5}{|l|}{ Any medical diagnosis } \\
\hline No (ref.) & 1.00 & - & 1.00 & - \\
\hline Yes & 1.21 & $0.90-1.62$ & 1.65 & $1.33-2.05^{* * *}$ \\
\hline \multicolumn{5}{|l|}{ Statistics } \\
\hline Hosmer \& Lemeshow $\chi^{2}$-value & 10.88 & & 3.27 & \\
\hline
\end{tabular}

${ }^{*} P<0.05 ;{ }^{* *} P<0.07 ;{ }^{* *} P<0.001$

(ref. $)=$ reference category; $O R=$ odds ratio; $C I=$ confidence interval.

\begin{tabular}{|c|c|c|c|c|}
\hline \multirow[t]{2}{*}{ Variable } & \multicolumn{2}{|c|}{ Expatriate } & \multicolumn{2}{|c|}{ Local } \\
\hline & OR & $95 \% \mathrm{Cl}$ & OR & $95 \% \mathrm{Cl}$ \\
\hline \multicolumn{5}{|l|}{ Mother's employment } \\
\hline Private sector & - & - & 2.01 & $0.69-5.81$ \\
\hline Self-employed & - & - & 1.79 & $0.51-6.24$ \\
\hline Government sector & - & - & 2.55 & $1.58-4.13^{* * *}$ \\
\hline Not employed (ref.) & - & - & 1.00 & - \\
\hline \multicolumn{5}{|l|}{ Any medical diagnosis } \\
\hline No (ref.) & - & - & 1.00 & - \\
\hline Yes & 1.77 & $1.19-2.65^{* *}$ & 2.00 & $1.35-2.94^{* * *}$ \\
\hline \multicolumn{5}{|l|}{ Persistent wheeze } \\
\hline No (ref.) & 1.00 & - & 1.00 & - \\
\hline Yes & 1.97 & $1.24-3.13^{* *}$ & 2.39 & $1.52-3.78^{* * *}$ \\
\hline \multicolumn{5}{|l|}{ Persistent cough } \\
\hline No (ref.) & 1.00 & - & 1.00 & - \\
\hline Yes & 1.42 & $0.96-2.09$ & 1.23 & $0.87-1.88$ \\
\hline \multicolumn{5}{|l|}{ Statistics } \\
\hline Hosmer \& Lemeshow $\chi^{2}$-value & 5.12 & & & \\
\hline
\end{tabular}

${ }^{*} P<0.05 ;{ }^{* *} P<0.01 ;{ }^{* * *} P<0.001$

(ref. $)=$ reference category; $O R=$ odds ratio; $C I=$ confidence interval. 


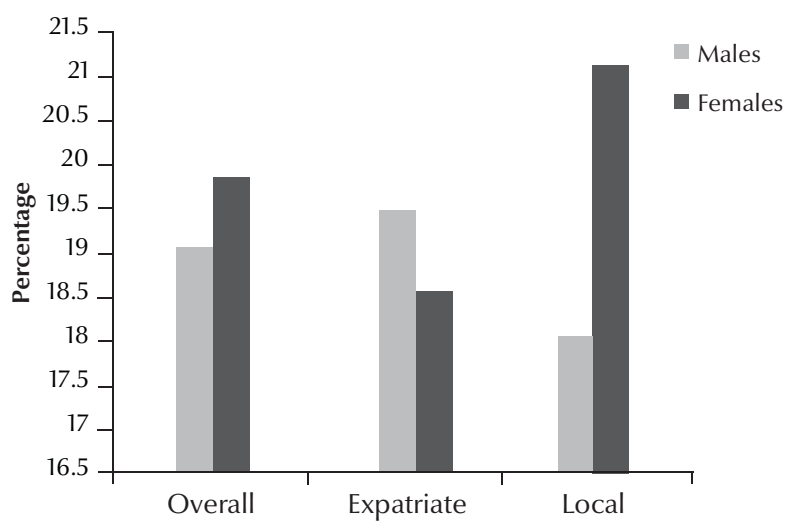

Figure 5 Having a routine physical check-up by male and female local and expatriate adolescents residing in the United Arab Emirates $(n=5652$ overall; $n=$ 2814 expatriate; $n=2736$ local)

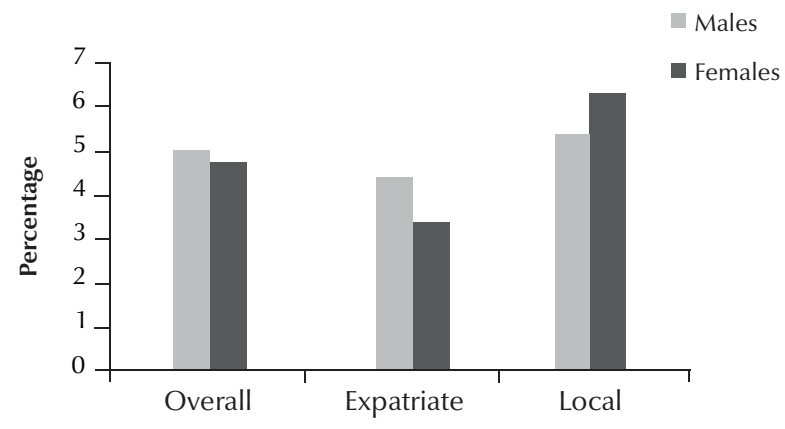

Figure 6 Travel to other countries for health care by male and female local and expatriate adolescents residing in the United Arab Emirates $(n=6201$ overall; $n=$ 3099 expatriate; $\boldsymbol{n}=\mathbf{2 9 8 7}$ local)

may have been subject to response bias. Sampling led to lower representations of adolescents who attended private schools in Dubai and among males who resided in Umm al-Quwain. This is relevant as the population of Dubai consists of a large proportion of expatriates; hence, the results related to the expatriate population in Dubai are likely to be biased. In addition, certain health predictors and health outcomes of great relevance to the adolescent sub-population were not included in the study; for example, $\mathrm{PHC}$ use related to sexual and reproductive health and the role of school health services or school-based medical check-ups as a predictor of healthseeking behaviour were not examined in the study. Furthermore, in relation to reasons for not receiving health care, the distinction between inability and unwillingness to obtain health services was not examined. Despite these limitations, this study contributed to general knowledge of PHC use and health care accessibility of UAE adolescents, which is a steppingstone for setting policy priorities to better serve this population.

\section{Conclusions}

This national study contributed to the literature by identifying the profile and predictors of PHC use among adolescents residing in the UAE. We found that many adolescents did not obtain health care when needed, for reasons such as dislike/fear of doctors and long waiting times. The majority of adolescents also did not have a routine physical health check-up without having a specific problem. In both the expatriate and local populations, monthly household income was a predictor of not receiving care. Our findings highlight the need for improvements to the health infrastructure, education campaigns to increase health-care-seeking behaviour and a national compulsory health insurance scheme to address some of the major barriers to health care access in the UAE. We have proposed some evidence-based strategies to overcome the most common barriers to service use in the UAE, whose effectiveness in the UAE context can be tested in future studies following their implementation.

\section{Acknowledgements}

Funding: The research design and data collection portions of this research were funded by the Zayed University Research Incentive Fund, Zayed University, Dubai, United Arab Emirates. The sponsor had no role in the study design, collection, analysis and interpretation of data, writing of the report and decision to submit the paper for publication

We thank Dr. Rania Dghaim who was involved in the design and data collection of the 'National Study of Population Health in the UAE (2007-2009).'

Competing interests: None declared.

\section{References}

1. Starfield B, Shi L, Macinko J. Contribution of primary care to health systems and health. Milbank Q. 2005;83(3):457-502. PMID:16202000
2. Kronfol NM. Access and barriers to health care delivery in Arab countries: a review. East Mediterr Health J. 2012 Dec;18(12):1239-46. PMID:23301399 
3. Health system profile: United Arab Emirates [Internet]. World Health Organization. Eastern Mediterranean Region, Regional Health Systems Observatory (http://apps.who.int/medicinedocs/documents/s17313e/s17313e.pdf, accessed 17 November 2014).

4. Al-Hosani H. Health for all in the United Arab Emirates. East Mediterr Health J. 2000 Jul;6(4):838-40. PMID:11794093

5. Margolis SA, Al-Marzouq S, Revel T, Reed RL. Patient satisfaction with primary health care services in the United Arab Emirates. Int J Qual Health Care. 2003 Jun;15(3):241-9. PMID:12803352

6. Barakat-Haddad C. Prevalence of high blood pressure, heart disease, thalassemia, sickle-cell anemia, and iron-deficiency anemia among the UAE adolescent population. J Environ Public Health. 2013;2013:680631. PMID:23606864

7. Ham P, Allen C. Adolescent health screening and counseling Am Fam Physician. 2012 Dec 15;86(12):1109-16. PMID:23316983

8. Norman GR, Streiner DL. Multiple regression. In: Norman GR, Streiner DL, editors. Biostatistics: the bare essentials. 3rd ed. Connecticut: People's Medical Publishing House; 2008.

9. Bertakis KD, Azari R, Helms LJ, Callahan EJ, Robbins JA. Gender differences in the utilization of health care services. J Fam Pract. 2000 Feb;49(2):147-52. PMID:10718692

10. Noone JH, Stephens C. Men, masculine identities, and health care utilisation. Sociol Health Illn. 2008 Jul;30(5):711-25. PMID:18564976

11. Hunt K, Adamson J, Hewitt C, Nazareth I. Do women consult more than men? A review of gender and consultation for back pain and headache. J Health Serv Res Policy. 2011 Apr;16(2):108-17. PMID:20819913
12. Michael M, Schaffer SD, Egan PL, Little BB, Pritchard PS. Improving wait times and patient satisfaction in primary care. J Healthc Qual. 2013 Mar-Apr;35(2):50-9, quiz 59-60. PMID:23480405

13. Fournier J, Heale R, Rietze LL. I can't wait: advanced access decreases wait times in primary healthcare. Healthc Q. 2012;15(1):64-8. PMID:22354058

14. Shook M. Transportation barriers and health access for patient attending a community health center. Field area paper. Portland (OR): Portland State Unviersity; 2005. (http://web.pdx. edu/ jdill/Shook_access_transportation_chc.pdf, accessed 4 February 2014)

15. Anthony MM, Walting MA. Overcoming medical phobias: how to conquer fear of blood, needles, doctors \& dentists. Oakland: New Harbinger Publications; 2006.

16. Heck KE, Parker JD. Family structure, socioeconomic status, and access to health care for children. Health Serv Res. 2002 Feb;37(1):173-86. PMID:11949919

17. Leininger LJ, Ziol-Guest KM. Reexamining the effects of family structure on children's access to care: the single-father family. Health Serv Res. 2008 Feb;43(1 Pt 1):117-33. PMID:18211521

18. Minkovitz CS, O'Campo PJ, Chen YH, Grason HA. Associations between maternal and child health status and patterns of medical care use. Ambul Pediatr. 2002 Mar-Apr;2(2):85-92. PMID:11926838

19. Health Authority Abu Dhabi [Internet] (http://www.haad.ae/ haad/, accessed 7 July 2014).

20. Bijur PE, Trumble A, Harel Y, Overpeck MD, Jones D, Scheidt PC. Sports and recreation injuries in US children and adolescents. Arch Pediatr Adolesc Med. 1995 Sep;149(9):1009-16. PMID:7655585 